\title{
Del procesalismo rígido a la moderniza- ción del arbitraje en el Ecuador: Aplicación de normas no domésticas en el arbitraje local ${ }_{-* *}$
}

\author{
Eduardo Carmigniani*** \\ Carla Cepeda**** \\ Bernarda Muriel ${ }^{* * * * *}$ \\ Recibido/Received: 16/08/2018 \\ Aceptado/Accepted: 17/08/2018
}

SUMARIO: 1. Introducción. 2. La autonomía de la voluntad. 2.1 Los reglamentos de arbitraje. 2.2 El poder de los árbitros. 2.3 Directrices sobre arbitraje internacional. 2.4 Límites: orden público y debido proceso. 2.4.1 Orden público. 2.4.2 Debido proceso. 3. El problema real: el ritualismo cultural. 4. Conclusiones.

Palabras Clave: modernización, arbitraje local, normas internacionales, flexibilidad.

* El presente artículo se publicó también en el libro Experiencias y Retos del Ecuador en el Arbitraje de Inversión y Comercial de la Cámara de Comercio Internacional.

** Un especial reconocimiento y agradecimiento a Ana Isabel Cobo por su eficiente y desinteresada participación en la investigación y revisión de este artículo.

*** Socio de Carmigniani Pérez Abogados. Abogado por la Universidad Católica Santiago de Guayaquil. Correo electrónico: ecarmi@cplaw.ec

**** Asociada de Carmigniani Pérez Abogados. Abogada por la Universidad San Francisco de Quito. Correo electrónico: ccepeda@cplaw.ec

***** Asociada de Carmigniani Pérez Abogados. Abogada por la Universidad San Francisco de Quito. Correo electrónico: bmuriel@cplaw.ec

E. Carmigniani, C. Cepeda, B. Muriel, "Del procesalismo rígido a la modernización del arbitraje en el Ecuador: Aplicación de normas no domésticas en el arbitraje local", Revista Ecuatoriana de Arbitraje, No. 9, 2017. 
Del procesalismo rígido a la modernización del arbitraje en el Ecuador: Aplicación de normas no domésticas en el arbitraje local

KEYWORDS: modernization, local arbitration, international rules, flexibility.

RESUMEN: En este artículo se discutirá una de las problemáticas más desafiantes que enfrenta el arbitraje ecuatoriano hoy en día: la posibilidad de aplicar en el arbitraje local reglas procesales disintas a las domésticas. Este estudio pretende demostrar que la incorporación de reglas procesales no domésticas en el arbitraje local no solo es admisible, sino deseable a efectos de fortalecer los principios de primacía de autonomía de la voluntad y flexibilidad del proceso arbitral. Se discutirá la importancia que estos principios tienen en materia de arbitraje, en qué consiste su aplicación y sus límites. Se analizará también la aplicación de la normativa procesal no doméstica en el arbitraje interno y casos específicos en los que se lo ha hecho. Finalmente, se planteará el reto que enfrenta el Ecuador: superar el excesivo formalismo procesalista del arbitraje interno.

Aвstract: This article will discuss one of the most challenging problems Ecuadorian arbitration faces nowadays: the possibility of applying on local arbitration different procedural rules than the domestic ones. This study tries to demonstrate that the incorporation of non-domestic procedural rules on local arbitration is not only admissible, but also desirable in order to strengthen the principles of autonomy of will and flexibility of the arbitral procedure. We will discuss the importance of these principles within arbitration, how do they apply and their limits. We will also analyze the application of non-domestic procedural rules on internal arbitration and specific cases in which this has been already made. Finally, we will explain the challenge Ecuador is facing: to overcome the excessive procedural formalism of local arbitration. 


\section{INTRODUCCIÓN}

La flexibilidad, omisión de ritualismos y eficiencia son atributos esenciales para el buen funcionamiento del arbitraje y para que las industrias prefieran este sistema sobre otros mecanismos de resolución de disputas ${ }^{1}$. Las reglas de procedimiento en el arbitraje varían (i) por el lugar geográfico en el que se aplican; (ii) por la época en la que se desarrollan las disputas y (iii) por la materia que se discute. En algunos casos, los procedimientos arbitrales pueden ser informales y flexibles, alejándose sustancialmente de los procedimientos previstos para la justicia ordinaria ${ }^{2}$. En otros casos, el manejo del arbitraje continúa siendo extremadamente formalista, replicando los mecanismos previstos para la justicia ordinaria ${ }^{3}$. Lo cierto es que -hoy en día- el arbitraje es atractivo para los negocios nacionales e internacionales porque asegura una resolución neutra, especializada y eficiente de su controversia. En consecuencia, su óptimo funcionamiento -tanto nacional como internacional- depende de que estos atributos se garanticen. En este sentido, el proceso arbitral debe evolucionar y adaptarse a las necesidades de las relaciones de comercio, ofreciendo en lo posible prácticas uniformes, de tal manera que sus usuarios se encuentren familiarizados con este sistema. Por supuesto, debe intentar garantizar una resolución de calidad. Solo de esta manera continuará siendo atractivo.

En este artículo se plantea como admisible que en los arbitrajes internos en Ecuador se adopte reglas procesales modernas, aunque no domésticas, que permitan un más eficiente manejo de los procedimientos. Se plantea también los distintos mecanismos a través de los cuales puede conseguírselo.

1. G. BoRn, International Commercial Arbitration, 2da Ed., Kluwer Law, 2014, p. 62.

2. Ídem, p. 63.

3. Ibídem. 
Del procesalismo rígido a la modernización del arbitraje en el Ecuador: Aplicación de normas no domésticas en el arbitraje local

\section{LA AUTONOMíA DE LA VOLUNTAD}

No está en discusión que la autonomía de la voluntad es el pilar fundamental sobre el que se asienta el arbitraje. Por eso en general las partes tienen derecho a estructurar el procedimiento de acuerdo con las circunstancias particulares del caso en concreto. En palabras de CAIVANO:

si hubiéramos de subrayar sólo una de sus condiciones favorables [del arbitraje], sin duda anotaríamos la flexibilidad, pues permite a las partes implementar un sistema a la medida de cada caso. Las partes pueden construir el arbitraje que mejor atienda sus necesidades y las particularidades del caso, sin por ello perder efectividad ${ }^{4}$.

El derecho de las partes a diseñar el procedimiento arbitral que mejor acomode a sus necesidades está reconocido categóricamente en el ordenamiento jurídico ecuatoriano. La Ley de Arbitraje y Mediación (en adelante, LAM), inspirada en el principio de flexibilidad de la Ley Modelo de la Comisión de las Naciones Unidas para el Derecho Mercantil Internacional sobre arbitraje comercial (en adelante, Ley Modelo) ${ }^{5}$, dice en su artículo 38 que "el arbitraje se sujetará a las normas de procedimiento señaladas en esta Ley, al procedimiento establecido en los centros de arbitraje, al determinado en el convenio arbitral o al que las partes escojan $[\ldots]^{\prime \prime 6}$ (énfasis añadido).

Es claro entonces que el principio de autonomía de la voluntad en materia de arbitraje en Ecuador no sólo garantiza la celebración de convenios de arbitraje, sino que quienes lo hacen tienen plena facultad para convenir las reglas del procedimiento ${ }^{7}$, en el propio convenio arbitral, o después. Las partes son dueñas

4. R. CAIVANO, El arbitraje: Nociones Introductorias, p. 7, http://www.derecho-comercial.com/Doctrina/ Arb-001.pdf (05/07/2018).

5. Report of the Secretary-General on Possible Features of a Model Law on international Commercial Arbitration, UN Doc. A/CN/9/207, XII, Year Book UNICTRAL, 1981, p. 78: "Probably the most important principle on which the Model Law should be based is the freedom of the parties in order to facilitate the proper functioning of international commercial arbitrations according to their expectations".

6. Ley de Arbitraje y Mediación (LAM), Art. 38, RO No. 417, 14/12/2006.

7. LAM, N. 6, Art. 38. 
de sus conflictos y tienen, en general, derecho a adecuar el procedimiento a sus particulares intereses.

En el sistema jurisdiccional, la normativa procesal, por el hecho de referirse a una de las funciones del Estado, es de derecho público ${ }^{8}$, pues regula la organización y el funcionamiento de la actividad jurisdiccional del Estado, las instituciones del proceso, su desarrollo y efectos ${ }^{9}$. En este sentido, toda la actividad jurisdiccional está sometida al principio de legalidad ${ }^{10}$. En un proceso judicial las partes y los jueces deben acatar expresamente las disposiciones del ordenamiento jurídico controlando que su actuación se apegue a la ley.

Por el contrario, dado que el arbitraje está fundado en el principio de la autonomía de la voluntad, las partes tienen el derecho de configurar el procedimiento, sea en el propio convenio arbitral, sea después ${ }^{11}$. CREMADES expone con claridad esta distinción entre el proceso arbitral y el judicial:

la posibilidad de configurar libremente el procedimiento distingue al arbitraje de la rigidez del proceso judicial, en donde estrictas reglas y formalismos delimitan los mecanismos para hacer valer las pretensiones de las partes [...]. Pocas cuestiones se dejan en un proceso judicial al arbitrio de las partes o a la discrecionalidad del Juez, ya que uno y otro cuentan con unos cauces normativos, a través de los cuales se desarrollará forzosamente el proceso $^{12}$ (énfasis añadido).

8. Véase, H. Devis EchandíA, Compendio de Derecho Procesal, 11va Ed., Temis, 2012, p. 6; E. Véscovi, Teoría general del proceso, 2da Ed., Temis, 2006, p. 8.

9. E. VÉSCOVI, N. 8, p. 8.

10. Código Orgánico de la Función Judicial, Art. 8, RO No. 544, 09/3/2009.

Art. 8.- "Las juezas y jueces solo están sometidos en el ejercicio de la potestad jurisdiccional a la Constitución, a los instrumentos internacionales de derechos humanos y a la ley. Al ejercerla, son independientes incluso frente a los demás órganos de la Función Judicial”.

11. LAM, N. 6, Art. 38.

Art. 38.- "El arbitraje se sujetará a las normas de procedimiento señaladas en esta Ley, al procedimiento establecido en los centros de arbitraje, al determinado en el convenio arbitral o al que las partes escojan, sin perjuicio de las normas supletorias que sean aplicables".

12. B. Cremades, "Consolidación de la Autonomía de la Voluntad en España: El Convenio Arbitral", Tratado de Derecho Arbitral Carlos Alberto Soto Coaguila El Convenio Arbitral, Instituto Peruano de Arbitraje, 2011, p. 665. 
Del procesalismo rígido a la modernización del arbitraje en el Ecuador: Aplicación de normas no domésticas en el arbitraje local

En definitiva, el principio de autonomía de la voluntad "permite que las partes pacten y diseñen reglas que más convengan a su particular relación. Esta interacción entre las partes tiene características similares a las de un orden espontáneo: la ausencia de planificación, de rigidez y de inmutabilidad"13. Por lo tanto, el carácter negocial de la normativa procesal del arbitraje es una consecuencia lógica de la naturaleza consensual de la institución.

\subsection{Los reglamentos de arbitraje}

El diseño de las partes de su procedimiento arbitral puede adoptar varias formas. El propio convenio arbitral puede contener reglas muy detalladas, por ejemplo. Pero es muy común que no se lo haga y que más bien las partes opten por encomendar la administración de su arbitraje $\mathrm{e}^{14}$ a una institución especializada y permanente, que cuenta con un reglamento propio, que se entiende incorporado al convenio arbitral.

Las razones para escoger a una institución específica para que administre un arbitraje generalmente son su reputación, familiaridad con sus reglas, conocimiento previo sobre los costos del arbitraje y la conveniencia de aplicar determinada normativa ${ }^{15}$. En consecuencia, el éxito de una institución arbitral dependerá -en gran medida- de que ofrezca reglas procedimentales flexibles, que puedan ajustarse a las necesidades de las partes y a modernas prácticas generalmente aceptadas por la comunidad arbitral.

La facultad que tienen los centros para establecer reglas de procedimiento está reconocida expresamente en el artículo 38 de la $\mathrm{LAM}^{16}$. Es completamente admisible por lo tanto que las insti-

\footnotetext{
13. A. Galindo y H. García, "Relación entre el Código Orgánico General de Procesos y el procedimiento arbitral", Revista Ecuatoriana de Arbitraje, No. 6, 2014, p. 56.

14. LAM, N. 6, Art. 2.

15. Queen Mary University of London, International Arbitration: Corporate Attitudes and Practices, 2008, p. 15. The results are consistent with the 2006 Study. Citado por G. CORDERO-Moss (Ed.), International Commercial Arbitration: Different Forms and their Features, Cambridge University Press, 2014, p. 66.

16. LAM, N. 6, Art. 38.
} 
tuciones arbitrales adopten reglamentos flexibles, que permitan ajustar los procedimientos a las necesidades específicas de las partes. Eso puede hacerse mediante referencia a normativas no domésticas, o estándares internacionales. También confiriendo expreso poder a los tribunales arbitrales para que gobiernen el procedimiento en defecto del acuerdo de las partes.

\subsection{El poder de los árbitros}

La naturaleza negocial del arbitraje también se evidencia en otro momento. Adicional al acuerdo que existe entre las partes para que sus disputas se resuelvan mediante arbitraje, también surge una relación consensual entre ellas y el tribunal arbitral que decidirá su controversia. Este último negocio jurídico lleva el nombre de receptum arbitrii ${ }^{17}$. La LAM prescribe en su artículo 17 que los árbitros designados "dentro de tres días de haber sido notificados, deberán aceptar o no el cargo"18. Al momento de la aceptación nace entre las partes y el tribunal arbitral el mencionado contrato ${ }^{19}$. En virtud de este acuerdo, los árbitros quedan obligados a: (i) resolver la controversia de manera definitiva de conformidad con los principios y la normativa aplicable; (ii) conducir el proceso de manera imparcial, independiente y diligente; (iii) garantizar el debido proceso; (iv) culminar su tarea con la emisión del laudo; (vi) procurar que el laudo sea ejecutable ${ }^{20}$.

Ya está visto que, por lo general, corresponde a las partes la elección de la normativa procesal aplicable a su controversia. Sin embargo, en virtud del receptum arbitrii "en el caso de que las par-

17. Concepto que surge en el derecho romano, durante el periodo de Justiniano y que hace alusión a un contrato (pactum) celebrado entre el arbiter y las partes. Para algunos autores el receptum es un pacto o contrato, pero no una mera y simple declaración del arbiter de su voluntad de juzgar; sin embargo, otros admiten la existencia de un juramento del arbiter para asegurar a las partes que haría el arbitraje con la mejor conciencia y voluntad. Sobre el concepto de receptum arbitrii. Véase C. GuTIERREZ, Receptum Arbitrii, RUA, No. 6, 1991.

18. LAM, N. 6, Art. 17.

19. P. Fouchard, E. Gaillard y B. Goldman, Traité de l'arbitrage commercial international, Litec, 1996, p. 618. Citado por R. CAIVANo, El Contrato entre las partes y los árbitros en el Código Civil y Comercial, 2015, p. 1.

20. J. M. MARChÁN y X. ANDRADE, "El Arbitraje Comercial Internacional en Ecuador: marco legal y jurisprudencial”, en C. CONEJERO Roos et al., El arbitraje internacional comercial en Iberoamérica: marco legal y jurisprudencial, 2da Ed., 2012, p. 363. 
Del procesalismo rígido a la modernización del arbitraje en el Ecuador: Aplicación de normas no domésticas en el arbitraje local

tes no hayan acordado las normas de procedimiento, la responsabilidad de dirigirlo pasará al tribunal arbitral, quien para estos efectos podrá cumplir su misión del modo que estime más apropiado, teniendo siempre en consideración los principios y normas de la ley" ${ }^{\prime 21}$. Es decir, los árbitros están obligados a determinar las normas del procedimiento cuando las partes han omitido hacerlo.

La Ley Modelo en su artículo 19, numeral 2 establece que "a falta de acuerdo [de las partes], el tribunal arbitral podrá, con sujeción a lo dispuesto en la presente Ley, dirigir el arbitraje del modo que considere apropiado. Esta facultad conferida al tribunal arbitral incluye la determinación, admisibilidad, la pertinencia y el valor de las pruebas" 22 . De acuerdo con la nota explicativa de la Ley Modelo, la facultad discrecional supletoria del Tribunal Arbitral:

es igualmente importante pues permite que éste sustancie las actuaciones según las características especiales de cada caso, sin las limitaciones impuestas por la legislación interna que suele aplicarse, incluso la que rige la práctica de la prueba. Además proporciona la base para dar muestras de iniciativa a fin de solucionar toda cuestión procesal no contemplada en el acuerdo de arbitraje ni en la Ley Modelo ${ }^{23}$ (énfasis añadido).

En esta línea, la LAM, inspirada en la Ley Modelo, reconoce la potestad del tribunal para regular las reglas que regirán el arbitraje. Su artículo 17 faculta expresamente al presidente del tribunal arbitral a sustanciar y dirigir el proceso ${ }^{24}$. Los reglamentos de las instituciones administradoras de arbitraje, sobre la base de la capacidad que les confiere el artículo 38 de la LAM para establecer reglas de procedimiento, también pueden conferir expreso poder a los tribunales arbitrales para que gobiernen el procedimiento en defecto del acuerdo de las partes.

21. E. Picand Albónico, Arbitraje Comercial Internacional, Tomo I, Editorial Jurídica Chile, 2005, p. 324. Citado por C. Coronel Jones, “Arbitraje y Procedimiento", Iuris Dictio, No. 11, 2007, p. 38.

22. Ley Modelo CNUDMI sobre Arbitraje Comercial Internacional de 1985 con las enmiendas aprobadas en 2006, (2008), Art. 19(2).

23. Nota explicativa de la secretaría de la CNUDMI acerca de la Ley Modelo sobre Arbitraje Comercial Internacional de 1985, en su versión enmendada en 2006, pp. 35-36.

24. LAM, N. 6, Art. 17. 
En el ejercicio de esa potestad el tribunal arbitral puede aplicar normativa procesal no doméstica. No existe prohibición legal para ello.

\subsection{Directrices sobre arbitraje internacional}

Internacionalmente existen reglas o directrices, de general aceptación, que han sido elaboradas por instituciones u organismos profesionales en la materia ${ }^{25}$. Algunas de ellas han alcanzado un importante reconocimiento en la comunidad arbitral, de tal manera que, su aplicación es ampliamente aceptada y deseable ${ }^{26}$. Entre las directrices más destacadas se encuentran:

(i) Las Reglas de la International Bar Association (en adelante, IBA) sobre Práctica de Prueba en el Arbitraje (2010). Estas directrices establecen disposiciones detalladas sobre la metodología para la presentación y admisión de evidencia durante el proceso arbitral ${ }^{27}$;

(ii) Directrices de la IBA sobre los Conflictos de Intereses en el Arbitraje Internacional (2004). Esta normativa se encuentra diseñada para establecer estándares éticos que garantizan la independencia e imparcialidad de los árbitros ${ }^{28}$. Así, plantean una serie de situaciones específicas que se clasifican según su importancia o no para generar dudas razonables sobre su independencia e imparcialidad. Además, establecen el deber de develar cualquier información que consideren relevante en este ámbito ${ }^{29}$;

(iii) Directrices de la IBA sobre Representación de Parte en el Arbitraje Internacional (2013). Estas directrices proponen guías sobre la conducta que se espera de los abogados y representantes de las partes durante el proceso arbitral ${ }^{30}$. Se encuen-

25. A. REDFERn et al., International Arbitration, 5ta Ed., Oxford University Press, 2009, p. 66.

26. Ibídem.

27. International Bar Association Council, Reglas de la IBA sobre Práctica de Prueba en el Arbitraje, 29/05/2010. Véase, <goo.gl/GBg6ET>.

28. International Bar Association Council, Directrices de la IBA sobre Conflictos de Intereses en el Arbitraje Internacional, Norma General 3, 22/05/2014, <goo.gl/12FbqE $>$.

29. Ibídem.

30. International Bar Association Council, Directrices de la IBA sobre Representación de Parte en el Arbitraje Internacional, 25/05/2013. Véase, <goo.gl/oNTdqZ>. 
Del procesalismo rígido a la modernización del arbitraje en el Ecuador: Aplicación de normas no domésticas en el arbitraje local

tran inspiradas bajo el principio de que los representantes deben actuar con integridad y honestidad. En esta línea, se rechaza toda conducta maliciosa, tendiente a retrasar o entorpecer la conducción efectiva del arbitraje ${ }^{31}$.

Directrices como las relatadas son mecanismos normativos de suma relevancia y utilidad para el gobierno de los procedimientos arbitrales. Su aplicación en el arbitraje interno ecuatoriano puede darse al amparo de algunos supuestos: (i) por acuerdo de las partes; (ii) por referencia expresa del reglamento de arbitraje al que las partes se hubiesen sometido y (iii) por decisión del tribunal arbitral, en defecto de acuerdo de las partes, en ejercicio del deber de conducir de manera efectiva el arbitraje ${ }^{32}$.

En el arbitraje interno ecuatoriano ya existen precedentes en los que estas directrices se han aplicado.

Un primer ejemplo es el caso Chaparro c. Ecuador ${ }^{33}$. En este caso se constituyó un tribunal arbitral independiente para resolver sobre la cuantificación de daños y perjuicios sufridos por el señor Chaparro por una violación de derechos humanos por parte del Estado ecuatoriano. En el arbitraje en mención, el tribunal arbitral decidió aplicar las Reglas IBA sobre Conflictos de Intereses para la recusación de uno de los miembros. El tribunal arbitral manifestó que:

[...] Todos estos conceptos [sobre imparcialidad] han sido recogidos de manera muy prolija por las Directrices de la International Bar Association (en adelante IBA) sobre conflictos de intereses en el arbitraje internacional, que constituye un catálogo de normas generales y casuística referencial más completo, de mayor aceptación y más usado en la comunidad actual del arbitraje.- Estas normas han sido cruciales para el desarrollo del arbitraje, puesto que proponen un test que de manera relativamente objetiva, aterriza el análisis subje-

31. G. Born, N. 1, p. 62.

32. Véase sección 2 .

33. Tribunal Independiente, Juan Carlos Chaparro Álvarez c. República del Ecuador, Laudo Final, 12/11/2012, en H. García LARriva (Coord.), Gaceta arbitral, No. 1, 2013. Tribunal Arbitral: Alicia Arias Salgado (presidente), Patricio Peña Romero (miembro del tribunal), Ignacio Vidal Maspons (miembro del tribunal). 
tivo que puede inmiscuirse dentro de la imparcialidad e independencia de los árbitros.- La directriz general 2 (b) propone que un árbitro deberá negarse a seguir actuando cuando sucedan "hechos o circunstancias tales que una tercera persona con buen juicio y con conocimiento del asunto consideraría que dan lugar a dudas justificadas acerca de la imparcialidad o independencia del árbitro", y en la directriz general 2 (c) añade que son "consideradas justificadas, aquellas dudas por las que una tercera persona con buen juicio y con conocimiento del asunto llegaría a la conclusión de que, probablemente, la decisión del árbitro podría verse influida por factores distintos a los méritos del caso presentados por las partes"-. Este estándar planteado implica un elevado nivel de imparcialidad e independencia pues imponen a los árbitros, no solo el ser sino el parecer imparciales en todo momento.

[...] Este Tribunal considera la insuficiencia que representan las causales del Código de Procedimiento Civil, en orden a garantizar la plena vigencia del derecho al debido proceso, en particular la garantía de un juez imparcial e independiente; esto producto de que nuestra norma procesal adjetiva responde a una época distinta y prueba evidente de aquello, es que el mismo artículo 856 numeral tercero limita la causal a juicios civiles y penales, dejando por fuera los demás tipos de pleitos y de otra indole, lo que quiere decir que el legislador quisiese que solo se recusase en estas materias, la respuesta simplemente es negativa, debido a que la limitación que hace el Código de Procedimiento Civil, responde a su antigüedad; por lo tanto, esta norma debe ser interpretada de manera extensiva y a la luz de las garantías constitucionales invocadas en la presente resolución ${ }^{34}$ (énfasis añadido).

En el mismo caso, las partes acordaron la aplicación de las Reglas de la IBA sobre Práctica de Prueba en Arbitraje Comercial Internacional ${ }^{35}$. Por este motivo, durante la etapa probatoria se adoptaron prácticas internacionales -no previstas en el arbitraje local en ese momento- como por ejemplo, el careo de peritos y la presentación de un informe conjunto realizado por los peritos de cada parte ${ }^{36}$.

34. Tribunal Independiente, N. 33, Recusación de Santiago Cuesta, pp. 342-346.

35. Tribunal Independiente, N. 33, p. 300, cita al pie No. 20.

"Para la práctica de la prueba se adoptó las Reglas IBA sobre la Práctica de Prueba en Arbitraje Internacional; y para la imparcialidad e independencia de los árbitros, las Directrices de la IBA sobre conflicto de intereses".

36. Tribunal Independiente, N. 33, p. 312, párr. 85. 
Del procesalismo rígido a la modernización del arbitraje en el Ecuador: Aplicación de normas no domésticas en el arbitraje local

Este caso reviste crucial importancia respecto a la implementación de normativa internacional en el arbitraje local, porque (i) el tribunal arbitral fue quien decidió sobre la implementación de normativa internacional para determinar la independencia e imparcialidad de uno de sus miembros, mostrando así su facultad para dirigir el proceso; (ii) el tribunal arbitral reconoció que la aplicación de las prácticas internacionales son más adecuadas y pertinentes que la normativa procesal prevista para la justicia ordinaria y (iii) las partes acordaron la aplicación de reglas internacionales para la práctica de la prueba, lo cual permitió que la controversia sea resuelta de manera acertada y satisfactoria a sus intereses.

Siguiendo esta tendencia, en el caso $06-16^{37}$ administrado por el Centro de Arbitraje y Mediación de la Cámara de Comercio Ecuatoriano Americana, se aplicaron las Directrices de la IBA sobre Conflictos de Intereses en Arbitraje Internacional en una resolución emitida por la Directora del Centro sobre la recusación de uno de los árbitros designados por las partes. La Directora sostuvo que de acuerdo con el numeral 3.1.2 de su Listado Naranja de las Reglas IBA sobre Conflictos de Intereses en Arbitraje Internacional existía el deber de revelación de los árbitros en el supuesto que: "[D]entro de los tres años anteriores el árbitro fue abogado de una de las partes o de una filial de éstas en un asunto independiente de la causa"38.

Finalmente, en el Centro de Arbitraje y Mediación de la Cámara de Comercio de Ambato de la Cámara de Industrias de Tungurahua, en los casos 003-2016, 004-2016 y 007-2016, se incluyeron -por acuerdo de las partes y el tribunal arbitral durante la Audiencia de Sustanciación- las reglas de la IBA para la Práctica de la Prueba en Arbitraje Internacional como disposiciones idóneas para conducir el arbitraje de manera efectiva.

\footnotetext{
37. Centro de Arbitraje y Mediación de la Cámara de Comercio Ecuatoriano Americana, Resolución sobre recusación del árbitro Álvaro Galindo Cardona, Proceso Arbitral No. 06-16, 03/08/2016, en E. CARMIGNIANI, H. GARCÍA, y C. CEPEDA, “Arbitraje en Ecuador: Desarrollo Jurisprudencial y Reformas Legales Recientes”, Revista Ecuatoriana de Arbitraje, No. 7, 2015, p. 197.

38. Ibídem.
} 
Los precedentes expuestos demuestran que en el Ecuador ya se han aplicado estas directrices localmente de manera efectiva y su beneficio es indudable porque: (i) resuelven vacíos que nuestra legislación local mantiene al momento; (ii) son guías elaboradas por expertos en la materia; (iii) han sido aceptadas por la comunidad arbitral más sofisticada; (iv) su funcionalidad ha sido ampliamente probada y (v) garantizan una resolución efectiva, acorde a los principios del debido proceso.

\subsection{Límites: orden público y debido proceso}

Como ha quedado claro, recurrir al arbitraje como mecanismo de resolución de controversias permite contar con un procedimiento en el que la voluntad de las partes prima. En ejercicio del principio de autonomía de la voluntad, las partes pueden diseñar el procedimiento, ya directamente (en el convenio arbitral o después), ya mediante referencia a un reglamento de arbitraje. También el tribunal arbitral, en ausencia de acuerdo de las partes, tiene el deber de organizar el procedimiento. Hay unos límites, sin embargo, para todos esos casos: el orden público y el debido proceso.

\subsubsection{Orden público}

El orden público es considerado como el conjunto de principios que versan sobre las nociones más básicas de moralidad y justicia de un Estado en particular ${ }^{39}$. Este constituye un límite a la voluntad de los particulares con el fin de garantizar que el interés general prevalezca sobre el interés personal ${ }^{40}$. Esta limitación se encuentra reconocida en materia de arbitraje. Así, el artículo 34(b) de la Ley Modelo señala que la anulación del laudo puede solicitarse cuando el tribunal compruebe que aquel es con-

39. F. GonzÁlez de Cossío, “Orden Público y Arbitrabilidad: Dúo Dinámico del Arbitraje”, Revista Internacional de Arbitraje, No. 2008, p. 4.

40. A. ACEDO, "El orden público actual como límite a la autonomía de la voluntad en la doctrina y la jurisprudencia", Anuario de la Facultad de Derecho, No. 14, 1996, p. 350. 
Del procesalismo rígido a la modernización del arbitraje en el Ecuador: Aplicación de normas no domésticas en el arbitraje local

trario al orden público del Estado ${ }^{41}$. De igual manera, la Convención de Nueva York sobre el Reconocimiento y la Ejecución de las Sentencias Arbitrales Extranjeras (Convención de Nueva York) prescribe en su artículo V(2)(b) que se podrá denegar el reconocimiento y ejecución de un laudo extranjero si la autoridad competente comprueba que se contraría el orden público del país requerido ${ }^{42}$. El orden público constituye una barrera para la autonomía de la voluntad.

Casos en los que vulneraría el orden público, por ejemplo, son la incorrecta conformación del tribunal arbitral, la violación de una regla fundamental de procedimiento o de ser el caso, la corrupción por parte de uno de los miembros del tribunal ${ }^{43}$.

En el Ecuador, las normas de orden público de índole procesal y arbitral son las relacionadas con la nulidad. En este sentido, las partes no pueden pactar causales en las que se acuerde que el proceso de nulidad se tramitará por vía arbitral. En la misma línea, no se podrá convenir el término para presentar esta acción o para disponer la competencia de la Corte Provincial para conocer la misma.

Es importante precisar que el orden público es un concepto distinto del derecho público, al cual pertenecen las normas procesales previstas para la justicia ordinaria. La Corte Suprema ecuatoriana los ha diferenciado nítidamente: "no son sinónimos, derecho público y orden público. No todo lo que es derecho público pertenece al orden público; en efecto, derecho público es un criterio de clasificación de la ley; orden público es un concepto político, social y jurídico" 44 . La libertad que tienen las partes para fijar las reglas aplicables a un caso en concreto se encuentra limi-

41. Ley Modelo CNUDMI, N. 22, Art. 34(b).

42. Convención sobre el Reconocimiento y la Ejecución de las Sentencias Arbitrales Extranjeras (Convención de Nueva York) (1958), Art. V(2)(b).

43. A. MeZgravis, El orden público sustantivo, el orden público procesal y la arbitrabilidad como causales de denegación del laudo: especial referencia a Venezuela y otros países de América Latina, Club Español de Arbitraje, III Congreso Internacional de Arbitraje, 2008, p. 26, cita al pie No. 54.

44. Primera Sala de lo Civil y Mercantil de la Corte Suprema de Justicia de Quito, Luis Enrique Figueroa Polo y Carmen Enriqueta Mendieta Riofrío c. Manuel Ignacio, Milton Gonzalo y Graciela Guillermina Bejarano Mendieta. Sentencia, 29/08/2002, Gaceta Judicial. Año CIII, Serie XVII No. 10. 
tada por el orden público, más no por las normas de derecho público previstas para la justicia ordinaria en los códigos procesales.

\subsubsection{Debido proceso}

Un segundo límite a la autonomía de la voluntad en el arbitraje es el respeto a las reglas básicas del debido proceso. Si bien la institución arbitral es de carácter negocial, esto no justifica que se desconozcan principios básicos sin los cuales no se podría hablar de justicia 45 . En efecto, en palabras de Rivera: "[e]n toda hipótesis los árbitros están obligados a respetar ciertos principios fundamentales, más allá de los cuales no puede verdaderamente concebirse una verdadera justicia" ${ }^{\prime 4}$.

El debido proceso es el conjunto de garantías y derechos mínimos para las partes, en los procedimientos de resolución de sus disputas ${ }^{47}$. La Constitución del Ecuador (artículo 76) detalla esas garantías básicas que deben observarse en todo proceso en el que se determinen derechos y obligaciones de cualquier orden ${ }^{48}$. Esto incluye al proceso arbitral. Estas garantías mínimas son, por ejemplo, que las partes tengan igualdad de condiciones para exponer argumentos y rebatirlos; a presentar pruebas y contradecirlas. Asimismo, el debido proceso incluye que las partes sean juzgadas por árbitros o jueces independientes, imparciales y competentes, que reciban una decisión motivada respaldada en argumentos fácticos y jurídicos.

En el arbitraje, la inobservancia del debido proceso puede conllevar a la anulación del laudo. La LAM establece en su artículo 31, entre las causales de nulidad, la inobservancia de reglas generalmente admitidas sobre el debido proceso. Las causales

45. H. Diaz CANDiA, El correcto funcionamiento expansivo del arbitraje (Teoría general del arbitraje), 2da Ed., Editorial Legis, 2013, p. 69.

46. J. C. Rivera, Arbitraje Comercial. Internacional y Doméstico, Lexis Nexis, 2007, p. 317, en J. SANTISTEVAN DE NORIEGA, “Arbitraje y proceso civil, ¿vecinos distantes?: El debido proceso en sede arbitral”, Ius La Revista, No. 37, p. 43.

47. H. Devis Echandía, N. 8, p. 706.

48. Constitución de la República del Ecuador, Art. 76, RO No. 449, 20/10/2008. 
Del procesalismo rígido a la modernización del arbitraje en el Ecuador: Aplicación de normas no domésticas en el arbitraje local

a) ${ }^{49}$, b) ${ }^{50}$ y c) ${ }^{51}$ de este artículo prescriben, en síntesis, que puede anularse el laudo por la falta de citación o notificación de una actuación procesal y esto haya privado o vulnerado el derecho a la defensa de una de las partes. Adicionalmente, la causal de anulación que alude al derecho de defensa también se reconoce en el artículo V(1)(b) de la Convención de Nueva York ${ }^{52}$. Es indiscutible que la autonomía de la voluntad tiene al respeto al debido proceso como otro límite infranqueable.

\section{EL PROBLEMA REAL: EL RITUALISMO CULTURAL}

El arbitraje interno era prácticamente inexistente en el Ecuador hasta 1997, cuando se promulgó la $\mathrm{LAM}^{53}$. Este cuerpo normativo, acompañado de una importante campaña de difusión por parte de la comunidad arbitral ecuatoriana, ha logrado que el arbitraje se desarrolle y se posicione como un sistema adecuado para la resolución de controversias comerciales locales ${ }^{54}$. La LAM, si bien no constituye una copia íntegra de la Ley Modelo y mantiene vacíos que podrían mejorarse en el tiempo, ha adoptado los principios fundamentales que deben ser adecuadamente entendidos y respetados por los usuarios del sistema ${ }^{55}$. En efecto, la normativa actualmente aplicable al arbitraje local, si es bien entendida puede garantizar la efectividad de los procedimientos arbitrales.

49. LAM, N. 6, Art. 31(a).

Art. 31. - "a) No se haya citado legalmente con la demanda y el juicio se ha seguido y terminado en rebeldía. Será preciso que la falta de citación haya impedido que el demandado deduzca sus excepciones o haga valer sus derechos y, además, que el demandado reclame por tal omisión al tiempo de intervenir en la controversia".

50. LAM, N. 6, Art. 31(b).

Art. 31. - "b) No se haya notificado a una de las partes con las providencias del tribunal y este hecho impida o limite el derecho de defensa de la parte".

51. LAM, N. 6, Art. 31(c).

Art. 31. - "c) Cuando no se hubiere convocado, no se hubiere notificado la convocatoria, o luego de convocada no se hubiere practicado las pruebas, a pesar de la existencia de hechos que deban justificarse".

52. Convención de Nueva York, N. 42, Art. V(1)(b).

53. LAM, N. 6.

54. E. Carmigniani y C. Cepeda, "Implementación (parcial) en Ecuador de principios de la Ley Modelo CNUDMI sobre arbitraje comercial. Retrospectiva histórica y necesidades", Revista Ecuatoriana de Arbitraje, No. 8, 2016, pp. 364-365.

55. Ídem, pp. 360-364. 
En este contexto, la problemática que inicialmente se ha planteado, de si a la luz del ordenamiento jurídico ecuatoriano es admisible la implementación de normativa no doméstica, merece respuesta positiva. En el Ecuador es posible aplicar esa normativa internacional en varios supuestos: (i) por acuerdo de las partes; (ii) por referencia expresa del reglamento de arbitraje al que las partes se hubiesen sometido y (iii) por decisión del tribunal arbitral, en defecto de acuerdo de las partes, en ejercicio del deber de conducir de manera efectiva el arbitraje $\mathrm{e}^{56}$.

El problema en verdad no es normativo. El problema es, por decirlo de alguna manera, cultural, por (i) escasa difusión; (ii) cierto temor que los operadores del sistema a alejarse de las prácticas ritualistas previstas para la justicia ordinaria y (iii) falta de cooperación entre la comunidad arbitral local y el sistema judicial para garantizar la efectividad del sistema. Como dice CORONEL JONES:

(...) dificultades, resistencias y temores, especialmente por parte de los operadores jurídicos: abogados, jueces e inclusive los propios árbitros quienes, formados con las ideas de respeto profundo a las normas procesales e inclusive inclinados hacia el formalismo y ritualismo en la práctica litigiosa, se ven abocados a lidiar con una modalidad de resolución de controversias que privilegia ampliamente el contenido sobre la forma, la agilidad y celeridad por sobre el rito y las fórmulas sacramentales ${ }^{57}$.

Para superar esas falencias es esencial que los operadores del sistema -partes, árbitros, centros de arbitraje e incluso jueces- entiendan que el arbitraje es un mecanismo en esencia negocial. Esto quiere decir que -mientras no se vulneren el orden público o el debido proceso- existe plena libertad y flexibilidad para que las partes o el tribunal arbitral diseñen el proceso más idóneo para la resolución del caso concreto. Esto incluye la posibilidad de aplicar las mejores prácticas y el marco normativo no doméstico en el arbitraje local.

56. Véase, sección 1.

57. C. Coronel Jones, N. 21, p. 37. 
Del procesalismo rígido a la modernización del arbitraje en el Ecuador: Aplicación de normas no domésticas en el arbitraje local

También tiene importante rol las instituciones arbitrales, que no solo deben profundizar el proceso de capacitación a los operadores del sistema arbitral, sino que deben modernizar sus reglamentos, adaptándolos, aunque sea por referencia, a las tendencias más modernas del arbitraje comercial internacional. Nuevamente, los únicos límites son el orden público y el debido proceso.

\section{Conclusiones}

La autonomía de la voluntad es el principio medular de la institución arbitral en el Ecuador y en el mundo; la naturaleza jurídica del arbitraje es en esencia negocial. De esta manera, en este mecanismo rige la premisa de que puede convenirse de procedimientos modernos y flexibles, en la medida en que no atenten contra el orden público o no vulneren las garantías mínimas del debido proceso.

Con este entendimiento, este estudio demuestra que el principio de autonomía de la voluntad admite la aplicación del marco jurídico no doméstico en el arbitraje local. La comunidad arbitral internacional ha desarrollado una serie de cuerpos normativos que regulan el arbitraje comercial de manera efectiva que se ajusta a las nuevas necesidades que surge en el comercio. Este marco normativo se caracteriza por sus constantes avances y mejoras en la formación y fortalecimiento de un sistema legal uniforme.

De acuerdo con los principios que inspiran nuestra legislación, la aplicación de normas internacionales en el arbitraje local no solo es jurídicamente admisible, sino beneficioso. La inclusión de prácticas modernas sólo representa ventajas para el sistema local, pues plantean respuestas satisfactorias a problemáticas que suelen presentarse en el decurso de los procedimientos arbitrales.

El reto es superar ataduras culturales. 